\title{
Fuzzy Estimate of the Development of Passenger Cars Production in the Czech Republic
}

\author{
Simona Hašková, ${ }^{1, *}$ \\ ${ }^{1}$ Institute of Technology and Business, School of Expertness and Valuation, Ceské Budejovice, Czech \\ Republic
}

\begin{abstract}
The global outbreak of the COVID-19 and the measures taken, disrupted fundamentally economies around the world. Almost all sectors were affected. The experts have long emphasised the Czech economy's dependence on the automotive industry. Car producers and companies linked to them have been loaded by severe difficulties after the pandemic outbreak. The article shows one of the constructive ways how to forecast a change in the passenger cars production in the Czech Republic in 2020. Metodologically we lean on a procedure of the fuzzy approach. The prediction itself cannot be derived from the series of historical data of the variables that are related to the target output variable as shown in the fuzzy prediction of GDP for 2018 by this author. Due to the extreme situation caused by pandemic outbreak, the role of expert predictions come intensively into play with their outcomes becoming the set of input data to the fuzzy model. The result of the fuzzy forcast of a change in the cars production in CZ for 2020 shows a greater drop than the official statistical model claims.
\end{abstract}

Keywords: passenger car production, automotive industry, fuzzy approach, fuzzy prediction

\section{Introduction}

The global COVID-19 pandemic outbreak and, as a result, the containment measures taken, have profoundly disrupted people's lives and the economies. The private and public demand, industrial production, supply chains, labour market, commodity prices, capital flows and foreign trade have been hit. Given the deepness of these shock changes, it is obvious that the European Union was affected by severe economic recession. The COVID19 outbreak trigged off a symmetric shock and due to tight economic connections of EU states the aggregate demand and supply shocks have intensified.

A current short time period forecast for 2021 shows incomplete recovery in most of countries [1]. It is clear that crisis impact and the way the individual EU states get over is

*Corresponding author: haskovas@post.cz 
going to be very uneven. How well and quickly the countries will pull together relies upon many external and internal factors [2]. There is not only the seriousness of the pandemic spread and the strictness of containment measures in play, but a great role belongs to particular economic exposures and pre-existing conditions as well as the policy responses.

The economic impacts of the current crises have been viewed from two basic levels [3] - the level of duration and the level of demand/supply side. For instance, the part time jobs and unemployment rise is expected in the short term occurring mainly on the demand side. Hysteresis occurrence in labour market has a potential of both supply and demand side and persisting in the medium term. Emerging market economy drop as a result of expected difficulties to rise external capital is rather perceived as a short-term effect affecting both the demand and supply side. Reorganization of cross border supply chain is expected from the long term affecting demand and supply side, etc.

Economists and politicians have often discussed the strong dependence of the Czech economy on the automotive industry and strong export focus on Germany. This dependence has been manifested most drastically during economic crises. The coronavirus outspread brought a significant decline in the production and car sales, automotive components and technologies. For example, Škoda Auto factory that is understood as the heart of the Czech industry stopped all lines. This factory creates on average for about five percent of GDP and accounts approximately $9 \%$ of exports. Some experts suggest to break out of the vulnerable car industry [4] and give more support to other domestic production and entrepreneurs. However, according to economists, such a scenario is not feasible; it is improbable that the Czech industry will be more radically reoriented in the future [5].

The aim of the paper is focused on a short term fuzzy prediction in the production of passenger cars in the Czech Republic. Due to external shock of the pandemic outbreak it is not possible to rely on a relevant sequence of historical data and the interventions of experts based on which the fuzzy prediction can be performed (see [6]). Therefore, we build the fuzzy prediction on the data based on expert scenarios of possible development of relevant variables. This procedure fully takes into account an extreme condition in which the economies currently appear.

\section{Methodology: The Introduction to Fuzzy Approach}

In the tasks of expert analysis or expert control of vaguely defined systems, the vague terms are usually presented by linguistic variables and their linguistic values (the terms), where the word "linguistic“ is used in the sense of „, communicated in natural language “.

The relationship between combinations of terms of the input linguistic variables and the output linguistic variable are given by a set of rules. The tool to mathematically solve these kind of tasks is the fuzzy logic on which the fuzzy approach is based (more in [7]).

The fuzzy approach purposefully modifies the assumptions and therefore the conclusions of the ,principle of extension" of fuzzy logic. This approach phases are visually demonstrated in Fig. 1 and concisely summarized as shown in Hašková [6]. and:

- The first phase is the fuzzification of the numerical vector $x=\left(x_{1}, \ldots, x_{n}\right)$ entering the relation $K$, in which the vector $x$ selects inferential rules relevant to its multicriteria evaluation. These are the rules $\left(\left(\mathrm{A}_{1 \mathrm{i}}, \ldots, \mathrm{A}_{\mathrm{nj}}\right), \mathrm{B}_{\mathrm{k}}\right) \in P$, in which terms' formalizations $\mathrm{A}_{1 \mathrm{i}}, \ldots, \mathrm{A}_{\mathrm{nj}}$ of the left side are all nonzero numbers $\mu_{\underline{A} l i}\left(x_{l}\right), \ldots, \mu_{\underline{A} n j}$ $\left(x_{n}\right)$.

- Moving from the symbolic notation $\left(\left(\mathrm{A}_{1 \mathrm{i}}, \ldots, \mathrm{A}_{\mathrm{nj}}\right), \mathrm{B}_{\mathrm{k}}\right)$ of the selected inference rule to its logic notation dependent on $x$ in the form $\left(\min \left\{\mu_{\underline{A} l i}\left(x_{1}\right), \ldots, \mu_{\underline{A} n j}\left(x_{n}\right)\right\}, \mu_{\underline{B} k}\right)=$ $\left(\mu_{\underline{A}^{*}}(x), \mu_{\underline{B} k}\right)$ we obtain a number $\mu_{\underline{A}^{*}}(x)$ indicating not only the degree of truthfulness that the situation characterized by the vector $x$ actually occurred, and 
therefore the degree of eligibility of the rule selection $\left(\left(A_{1 i}, \ldots, A_{n j}\right), B_{k}\right)$ to its solution, but also the degree of significance of the term $B_{k}$ in the multi-criteria evaluation of the vector $x . \mu_{\underline{B} k}: Y \rightarrow\langle 0,1\rangle$ is the standard membership function of the elements $y \in Y$ to the fuzzy set $\underline{B}_{k}$. On the other hand, $\mu_{B k}^{*}: Y \rightarrow\langle 0,1\rangle$ in the form $\mu_{\underline{B} k}^{*}(y)=\min \left\{\mu_{\underline{A}^{*}}(x), \mu_{\underline{B} k}(y)\right\}$ limits from above the function $\mu_{\underline{B} k}$ by means of the number $\mu_{\underline{A}}^{*}(x)$.

- The components of the relation $K$ will then be the elements of the set $P x=\left\{\mathrm{B}_{\mathrm{k}}\right.$ : $\left.\exists y:\left(\min \left\{\mu_{\underline{A}^{*}}(x), \mu_{\underline{k} k}(y)\right\}>0\right),\left(\left(\mathrm{A}_{1 \mathrm{i}}, \ldots, \mathrm{A}_{\mathrm{nj}}\right), \mathrm{B}_{\mathrm{k}}\right) \in P, y \in Y\right\}$. These are the partial intermediate results by which aggregation (logical sum) we obtain the formalized term $\underline{B}_{a g g}=\left\{\left(y, \mu_{a g g}(y)\right): y \in Y\right\}$ on $Y$, for which it applies (1)

$\mu_{\text {agg }}(y)=\max \left\{\min \left\{\mu_{\underline{A}^{*}}(x), \mu_{\underline{B} k}(y)\right\}:\left(\left(A_{1 i}, \ldots, A_{n j}\right), B_{k}\right) \in P, y \in Y\right\}$

- The final phase of the fuzzy approach is defuzzification, in which last step we obtain the output value $y_{x}$ of the multicriteria model of an alternative evaluation $\left(a_{1}, \ldots, a_{c}\right) \in A$ as the mean value of the elements $y \in \underline{B}_{a g g}$ weighted by the values $\mu_{\text {agg }}(y)$ of their significance - see (2). Therefore

$$
y_{x}=\int y \cdot \mu_{a g g}(y) d y / \int \mu_{a g g}(y) d y
$$

where $\int$ is the symbol of a definite integral over the universe $Y$ - more in detail in [8] and [9].

The process of the multi-criteria assessment of a short time prediction of the change in passenger cars production in the Czech Republic is illustrated in a solution to the specific task.

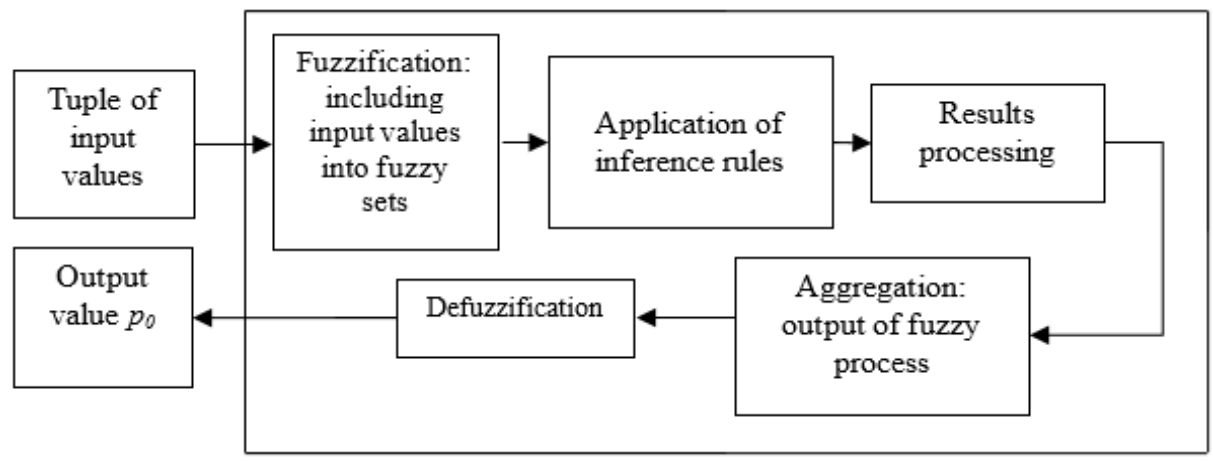

Fig. 1. Schematic representation of the multicriteria problem solving process within the fuzzy approach

Source: Own processing.

\section{Application - Assumptions and Entry Data of the Fuzzy Predictive Model}

The formulation of the fuzzy model of prediction of the next member of the time series has its specifics; we know a number of previous members of the resulting series of the target variable - these are historically measured data and data statistically predicted. Its 
consecutive values can be used in the prediction only if the economy has not appeared in a period of an extreme state, which deviates from the normal (expected) framework of its functioning.

In the case of a standard economic development, it would therefore be possible to estimate the current stage of development (decline, growth, stagnation), within which the prediction will fall when predicting the targeted variable - here, a year-on-year change in passenger cars production in the Czech Republic $\left(\triangle \mathrm{PS} \mathrm{CZ}_{\mathrm{CZ}} \%\right)$. This estimate would be also supported by the development of the historical part of input values of basic linguistic variables, on which $\mathrm{PS}_{\mathrm{CZ}} \%$ depends (albeit to a large extent vaguely). These are then reflected mainly in the values of the extreme limits (intervals), in which the result of the prediction would be searched - see, for example, the work [10], which shows a short-term prediction of the development of the GDP growth rate.

Next Tab. 1 shows the basal values of the input linguistic variables $\Delta \mathrm{GD}_{\mathrm{PG}} \%$ (a year-onyear change in Germany's gross domestic product), $\Delta \mathrm{AP}_{\mathrm{W}} \%$ (a year-on-year change in the worldwide cars production), $\Delta \mathrm{AP}_{\mathrm{G}} \%$ (a year-on-year change in the cars production in Germany) and the output linguistic variable $\Delta \mathrm{PS}_{\mathrm{CZ}} \%$ (a year-on-year change in the production of passenger cars in CZ) between the years 2009 - 2019 and their econometric forecast for the year 2020 .

Table 1. Basic macroeconomic data for fuzzy predicting models of the annual change in the production of passenger cars in $\mathrm{CZ}$

\begin{tabular}{|l|r|r|r|r|r|r|r|r|r|r|r|r|}
\hline ROK & $\mathbf{2 0 0 9}$ & $\mathbf{2 0 1 0}$ & $\mathbf{2 0 1 1}$ & $\mathbf{2 0 1 2}$ & $\mathbf{2 0 1 3}$ & $\mathbf{2 0 1 4}$ & $\mathbf{2 0 1 5}$ & $\mathbf{2 0 1 6}$ & $\mathbf{2 0 1 7}$ & $\mathbf{2 0 1 8}$ & $\mathbf{2 0 1 9}$ & \multicolumn{1}{|c|}{020} \\
\hline$\Delta \mathrm{GDP}_{\mathrm{G}} \%$ & $-5,69$ & 4,19 & 3,91 & 0,43 & 0,43 & 2,22 & 1,74 & 2,23 & 2,47 & 1,52 & 0,57 & $-6,95$ \\
\hline$\Delta \mathrm{AP}_{\mathrm{W}} \%$ & $-12,7$ & 24,2 & 3,4 & 5 & 3,4 & 3,4 & 1 & 4,4 & 2,1 & 0 & $-5,2$ & -22 \\
\hline$\Delta \mathrm{AP}_{\mathrm{G}} \%$ & -9 & 12 & 5,4 & $-8,5$ & 0 & 3,7 & 1,8 & 0 & $-1,8$ & $-8,9$ & $-7,8$ & $-17,2$ \\
\hline$\Delta \mathbf{P S}_{\mathrm{CZ}} \%$ & $\mathbf{4 , 1}$ & $\mathbf{1 0 , 3}$ & $\mathbf{1 1 , 6}$ & $\mathbf{- 1 , 6}$ & $\mathbf{- 3 , 9}$ & $\mathbf{1 0 , 5}$ & $\mathbf{4 , 2}$ & $\mathbf{8}$ & $\mathbf{5 , 2}$ & $\mathbf{1 , 7}$ & $\mathbf{- 0 , 6 8}$ & $\mathbf{- 3 0}$ \\
\hline
\end{tabular}

Source: [11], [12], [13] / own processing.

From the course of $\triangle \mathrm{PS}_{\mathrm{CZ}} \%$ it can be concluded that in the period $2016-2019$ the production of passenger cars in $\mathrm{CZ}$ was in a phase of decline, which, due to the „extreme“ the COVID-19 pandemic, will deepen significantly in the following period. Therefore, the characteristics of this historical data in Tab. 1 cannot be used for the formulation of the fuzzy predictive model for 2020 .

As already mentioned, the outbreak of the COVID-19 pandemic has led to an extreme exogenous economic shock, and the absence of a historically relevant precedent makes it impossible to capture the prediction using standard econometric models and fuzzy procedure as shown in [6]. As a result, any predictions are based on expert scenarios simulating possible shocks at a given set of input assumptions. It follows that the opinion of a knowledgeable expert becomes a major specificity of the fuzzy predictive model formulation. The experts take knowledge and available information into account through qualified scenario constructions, interventions in the model structure and the inference rule formulation.

It applies that the predictive model works with the dimensionless basal values of the output universe $Y$ and the input universes $U_{\mathrm{GDP}_{-} \mathrm{G}}, U_{\mathrm{AP}-\mathrm{W}}, U_{\mathrm{AP}_{-} \mathrm{G}}$ located within the interval $\langle 0,100\rangle$ and obtained by converting the entry values of the respective linguistic variables. The conversion of the inserted basal value $x$ of the universe $Y$ of the output linguistic variable to the dimensionless value $y \in Y$ is given by the formula $y=100 \cdot\left(x-x_{\text {min }}\right)$ / $\left(x_{\max }-x_{\min }\right)$, where $x_{\max }$, or respectively, $x_{\min }$ is the highest, or respectively, the lowest a priori (subjectively) expected result value. For the conversion in the opposite direction, $x=\left(y \cdot\left(x_{\max }-x_{\min }\right) / 100\right)+x_{\min }$ applies. 
If the predominant element strategy is chosen in formulating the system of inferential rules with three inputs, then for the conversion of the value $x$ of the universe of the input linguistic variable having a positive or featureless influence on the output linguistic variable it applies that $u=100 \cdot\left(x-x_{\min }\right) /\left(x_{\max }-x_{\min }\right)$. In the case of a negative influence on the output linguistic variable, $u=100-\left(100 \cdot\left(x-x_{\min }\right) /\left(x_{\max }-x_{\min }\right)\right)$ holds.

In our case, the output linguistic variable is a year-on-year change in the production of passenger cars in $\mathrm{CZ}$ in the year immediately following the historical period. The percentage increase in gross domestic product in Germany (GDP) indicates a positive effect - an increase in the growth of production of personal cars in CZ; a decrease of automotive production worldwide and in Germany $\left(\mathrm{AP}_{\mathrm{W}} \%, \mathrm{AP}_{\mathrm{G}} \%\right)$ tend to decelerate the car production in $\mathrm{CZ}$ (a negative impact).

\section{Results}

In order to estimate the targeted $\triangle \mathrm{PS}_{\mathrm{CZ}} \%$, the expert knowledge published in (Europian Economic Forecast from spring 2020 [14]) is used with three global scenarios for 2020 being considered. Scenario i. assumes a six-week "lockdown" with a global GDP decline of $8 \%$. A longer-term "lockdown" scenario ii. means a $15.5 \%$ decrease in GDP and scenario iii. works with the second wave of the pandemic, which would require additional measures and restrictions in autumn and winter 2020 - this assumes a $10.5 \%$ decline in GDP (the forecast in Tab. 1 for 2020 represents the scenario iii). The scenarios include assumptions such as duration of restrictive measures, sector demand, uncertainty, tourism activity, preventive savings, public distancing, automatic stabilizers, discretionary fiscal policy and liquidity support.

The formulation of the predictive fuzzy model for the year 2020 is based on the characteristics of these scenarios. Scenario i. reaches almost $76 \%$ of scenario iii (the baseline); scenario ii. accounts for approximately $148 \%$ of scenario iii. This delimitation allows the formulation of the limits in which the resulting forecast $\Delta \mathrm{PS}_{\mathrm{CZ}} \%$ for 2020 will apear: the result of the prediction for 2020 will be searched within the limits of the given values $x_{\max }=-44, x_{\min }=-23$, i.e., the maximum decrease - the baseline prediction in $2020 \mathrm{x}$ 1.48 , the minimal decrease - the baseline prediction in $2020 \times 0.76$.

The conversion of the $\Delta \mathrm{PS}_{\mathrm{CZ}} \% x$ value given by scenario iii. $x_{20} \approx 33 \mathrm{I}(100 \cdot(-30-(-$ $23)) /(-44-(-23)) \mid \approx 33)$. Analogously, for the recalculated vector input values $\left(x_{\mathrm{GDP}_{-} \mathrm{G}}\right.$, $\left.x_{\mathrm{AP} \_\mathrm{W}}, x_{\mathrm{AP} \_\mathrm{G}}\right)$ for the year 2020 we get an interval according to the formula (MAX [maximum decrease - baseline prediction 2020 x 1.48]; MIN [minimum decrease baseline prediction $2020 \times 0.76]$ ). The conversion of basic values in 2020 of the given inputs is driven as follows: $u=100 \cdot\left(x-x_{\min }\right) /\left(x_{\max }-x_{\min }\right)$ in the case of a positive influence on the output linguistic variable and $u=100-\left(100 \cdot\left(x-x_{\min }\right) /\left(x_{\max }-\right.\right.$ $\left.\left.x_{\min }\right)\right)$ in the case of a negative influence on the linguistic output.

- $\quad x_{\mathrm{GDP}_{-} \mathrm{G}}=100 \cdot \mathrm{|}(-6,95-(-5,3)) /(-10,3-(-5,3)) \mathrm{|}=33$;

- $\quad x_{\mathrm{AP} \_\mathrm{W}}=100-\mathrm{I}(100 \cdot(-22-(-16,7)) /(-32,6-(-29)) \mathrm{I}=47$;

- $\quad x_{\mathrm{AP} \_\mathrm{G}}=100-\mathrm{I}(100 \cdot(-17-(-13)) /(-33-(-25)) \mathrm{I}=50$.

Thus, the triple $(33 ; 47 ; 50) \in U=U_{\mathrm{GDP}_{-} \mathrm{G}} \times U_{\mathrm{AP}_{-} \mathrm{W}} \times U_{\mathrm{AP}_{-} \mathrm{G}}=\langle 0,100\rangle^{3}$ of internal (converted) input values has been created (see point 1 in section 2 ).

A coarser variant of this model with one inner and two boundary fuzzy sets for the terms low $(\underline{L})$, normal $(\underline{M})$ and high $(\underline{H})$ value well suits our purpose. The interval $U$ is divided into five sections by points a, b, c, d with the courses of membership functions (3): 
- $\mu_{\underline{L}}(x)=1$ for $x<\mathrm{a}, \mu_{\underline{L}}(x)=(\mathrm{b}-x) /(\mathrm{b}-\mathrm{a})$ for $\mathrm{a} \leq x<\mathrm{b}, \mu_{\underline{L}}(x)=0$ otherwise;

- $\quad \mu_{\underline{M}}(x)=(x-a) /(b-a)$ for $\mathrm{a} \leq x<\mathrm{b}, \mu_{\underline{M}}(x)=1$ for $\mathrm{b} \leq x<\mathrm{c}, \mu_{\underline{M}}(x)=$ $(\mathrm{d}-x) /(\mathrm{d}-\mathrm{c})$ for $\mathrm{c} \leq x<\mathrm{d}, \mu_{\underline{M}}(x)=0$ otherwise;

- $\mu_{\underline{H}}(x)=0$ for $x<\mathrm{c}, \mu_{\underline{H}}(x)=(x-\mathrm{c}) /(\mathrm{d}-\mathrm{c})$ for $\mathrm{c} \leq x<\mathrm{d}, \mu_{\underline{H}}(x)=1$ otherwise.

Because of the high external uncertainty (e.g., the uncertain impact of the pandemic on economies) and internal uncertainty of the model we choose the points a, b, c, d evenly distributed within the interval $U \in\langle 0,100\rangle$, in which $\mathrm{a}=20, \mathrm{~b}=40, \mathrm{c}=60, \mathrm{~d}=80$. Therefore, the courses of the membership functions of the converted output and all the converted inputs are identical (Fig. 2, in which these courses are plotted above the domain of universe $Y$ of converted values of the output linguistic variable):

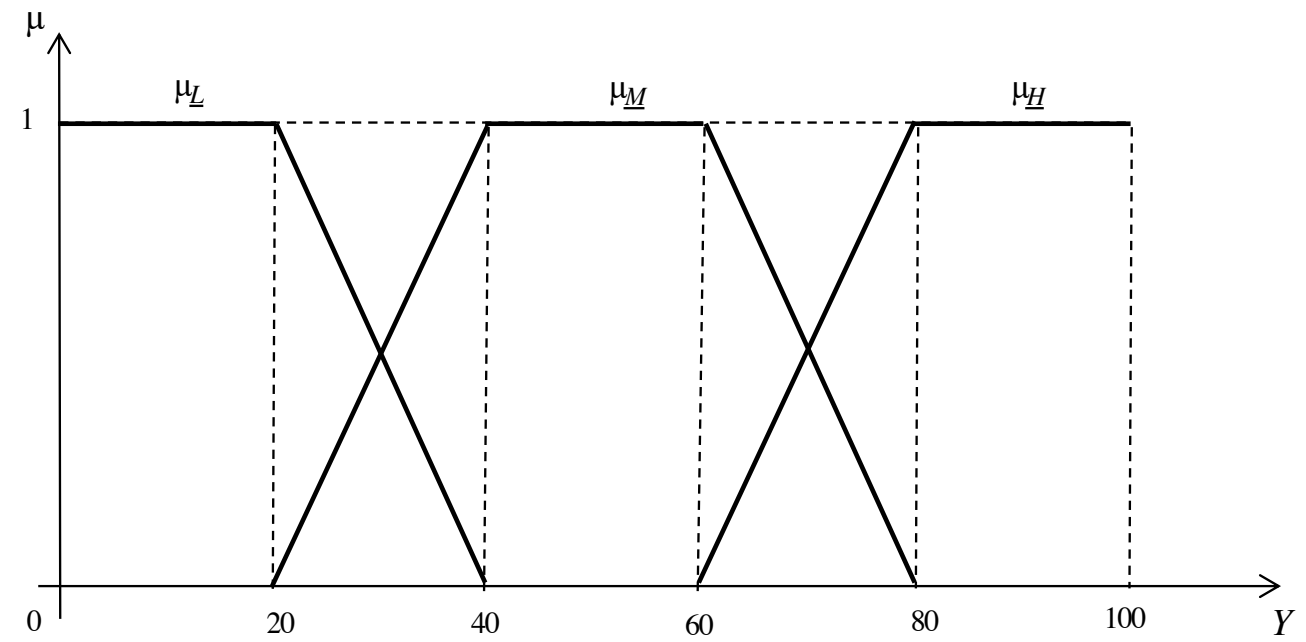

Fig. 2. Courses of the membership functions with even distribution of the points a, b, c, d within the interval values $y \in Y=\langle 0,100\rangle$

Source: Own processing.

The following fuzzification table Tab. 2 valid for $i=\mathrm{GDP}_{\mathrm{G}} \%, \mathrm{AP}_{\mathrm{W}} \%, \mathrm{AP}_{\mathrm{G}} \%$, whose elements are the values $\mu_{\underline{A i}}\left(u_{\mathrm{i}}\right)$, where index $\underline{A} \in\{\underline{L}, \underline{M}, \underline{H}\}$, is derived from the above stated equations and inequalities given by (3):

Table 2. Fuzzification table valid for $i=\mathrm{GDP}_{\mathrm{G}} \%, \mathrm{AP}_{\mathrm{W}} \%, \mathrm{AP}_{\mathrm{G}}$, whose elements are values $\mu_{\underline{A}}\left(x_{\mathrm{i}}\right)$, where $\underline{A}_{\mathrm{i}} \in\left\{\underline{L}_{\mathrm{i}}, \underline{M}_{\mathrm{i}}, \underline{H}_{\mathrm{i}}\right\}$

\begin{tabular}{|l|c|c|c|c|c|}
\hline Interval & $\boldsymbol{x}_{\mathbf{i}}<\mathbf{2 0}$ & $\mathbf{2 0} \leq \boldsymbol{x}_{\mathbf{i}}<\mathbf{4 0}$ & $\mathbf{4 0} \leq \boldsymbol{x}_{\mathbf{i}}<\mathbf{6 0}$ & $\mathbf{6 0} \leq \boldsymbol{x}_{\mathbf{i}}<\mathbf{8 0}$ & $\boldsymbol{x}_{\mathbf{i}} \geq \mathbf{8 0}$ \\
\hline$\underline{\boldsymbol{L}}_{\mathbf{i}}$ & 1 & $\left(40-x_{\mathrm{i}}\right) / 20$ & 0 & 0 & 0 \\
\hline$\underline{\boldsymbol{M}}_{\mathbf{i}}$ & 0 & $\left(x_{\mathrm{i}}-20\right) / 20$ & 1 & $\left(80-x_{\mathrm{i}}\right) / 20$ & 0 \\
\hline$\underline{\boldsymbol{H}}_{\mathbf{i}}$ & 0 & 0 & 0 & $\left(x_{\mathrm{i}}-60\right) / 20$ & 1 \\
\hline
\end{tabular}

Source: Own processing. 
In the fuzzification table, only non-zero elements are taken into account and with its help the set $X=\left\{\left(\underline{L}_{\mathrm{GDP}_{-} \mathrm{G}} ; 0.35\right),\left(\underline{M}_{\mathrm{GDP}_{-} \mathrm{G}} ; 0.65\right),\left(\underline{M}_{\mathrm{AP}_{-} \mathrm{W}} ; 1\right),\left(\underline{M}_{\mathrm{AP} \_\mathrm{G}} ; 1\right)\right\}$ is created.*

* Comment on creating a set $X$ using a fuzzification table:

- The value $x_{\mathrm{GDP} G}=33$ (for $\mathrm{i}=\mathrm{GDP}_{\mathrm{G}} \%$ ) falls within the interval of the second column; there are two non-zero elements in it - one $\left(\left(40-x_{\mathrm{i}}\right) / 20\right)$ in the line $\underline{L}_{\text {GDP_G }}$, gives after substituting $(40-33) / 20=0.35$, and therefore $\left(\underline{L}_{\mathrm{GDP}_{-} \mathrm{G}}\right.$; $0.35)$ - the other $\left(\left(x_{\mathrm{i}}-20\right) / 20\right)$ in the line $\underline{M}_{\text {GDP_G }}$, gives after substituting (33 - 20) $/ 20=0.65$, and therefore $\left(\underline{M}_{\mathrm{GDP}} \mathrm{G} ; 0.65\right)$.

- The value $x_{\mathrm{AP} \_\mathrm{W}}=47$ (for $\mathrm{i}=\mathrm{AP}_{\mathrm{W}} \%$ ) falls within the interval of the third column; there is one non-zero element (1) in it in the $\underline{M}_{\mathrm{AP}-\mathrm{W}}$ line, and therefore $\left(\underline{M}_{\mathrm{AP}-\mathrm{W}} ; 1\right)$.

- The value $x_{\mathrm{AP} \_\mathrm{G}}=50$ (for $\mathrm{i}=\mathrm{AP}_{\mathrm{G}} \%$ ) falls again within the interval of the third column; there is one non-zero element (1) in it in the $\underline{M}_{\mathrm{AP}-\mathrm{G}}$ line, and therefore $\left(\underline{M}_{\mathrm{AP}_{-} \mathrm{G}} ; 1\right)$.

A two-element set $L F=\left\{\left(\underline{L}_{\mathrm{GDP} \_\mathrm{G}}, \underline{M}_{\mathrm{AP} \_\mathrm{W}}, \underline{M}_{\mathrm{AP} \_\mathrm{G}}\right),\left(\underline{M}_{\mathrm{GDP} \_\mathrm{G}}, \underline{M}_{\mathrm{AP} \_\mathrm{W}}, \underline{M}_{\mathrm{AP} \_\mathrm{G}}\right)\right\}$ is formed from the set $X$. After applying the inference rules $F\left(\underline{L}_{\mathrm{GDP}_{\mathrm{G}}}, \underline{M}_{\mathrm{AP} \_\mathrm{W}}, \underline{M}_{\mathrm{AP} \mathrm{G}}\right)=\underline{M}$ and $F\left(\underline{M}_{\mathrm{GDP}_{-} \mathrm{G}}, \underline{M}_{\mathrm{AP} \mathrm{H}_{-}}, \underline{M}_{\mathrm{AP} \mathrm{G}}\right)=\underline{M}$ to triplets from $L F$, we can convert the general expression $\min \left\{\min \left\{\mu_{\underline{A} l}\left(x_{I}\right), \ldots, \mu_{\underline{A} n}\left(x_{n}\right)\right\}, \mu_{F(\underline{A} 1, \ldots, \underline{A n})}\right\}$ to a concrete form $\min \left\{\min \{0.35 ; 1 ; 1\}, \mu_{\underline{M}}\right\}=$ $\min \left\{0.35, \mu_{\underline{M}}\right\}=\mu_{\underline{M}}{ }^{*}: Y_{\underline{M}} \rightarrow(0,0.35\rangle$ in the first case and $\min \left\{\min \{0.65 ; 1 ; 1\}, \mu_{M}\right\}=$ $\min \left\{0.65, \mu_{\underline{M}}\right\}=\mu_{\underline{M}} * Y_{\underline{M}} \rightarrow(0,0.65\rangle$ in the second case. For the membership function $\mu_{\underline{A G G}}:\langle 33-100\rangle \rightarrow(0, \overline{1}\rangle$ to the fuzzy set $\underline{A G G}$ we get: $\mu_{\underline{A G G}}=\max \left\{\left(\mu_{\underline{M}}^{*} ; 0.35\right),\left(\mu_{\underline{M}}^{*}\right.\right.$; $0 . \overline{65})\}$, where $\mu_{\underline{M}}{ }^{*}:\langle 33-80\rangle \rightarrow(0 ; 0.65\rangle$, i.e. $\mu_{\text {agg }}(y)=0$ for $\bar{y}<33, \mu_{\underline{A G G}}(y)=0.65$ for $3 \overline{3} \leq$ $y \leq 67, \mu_{\underline{A G G}}(y)=(80-\mathrm{x}) / 20$ for $67 \leq y \leq 80, \mu_{\underline{A G G}}(y)=0$ for $y>80$ (see the strongly drawn contour in Fig. 3).

By an approximate numerical approximation of the values of the integrals in the formula for calculating the horizontal coordinate of the position of the center of gravity, see part 2 relation (2), the value $p_{0}$ representing the estimate of the value $\mathrm{PS}_{\mathrm{CZ}} \%$ for $2020 \mathrm{can}$ be estimated as $p_{0}=(0.65 \cdot(40+50+60+70) /(4 \cdot 0.65) \approx 52.5 \%$. After recalculation $x_{0}$ to $\Delta \mathrm{PS}_{\mathrm{CZ}} \%$, we get the predicted value of $\Delta \mathrm{PS}_{\mathrm{CZ}} \%=(52.5 \cdot(-44-(-23) / 100)-23) \approx-$ 34.

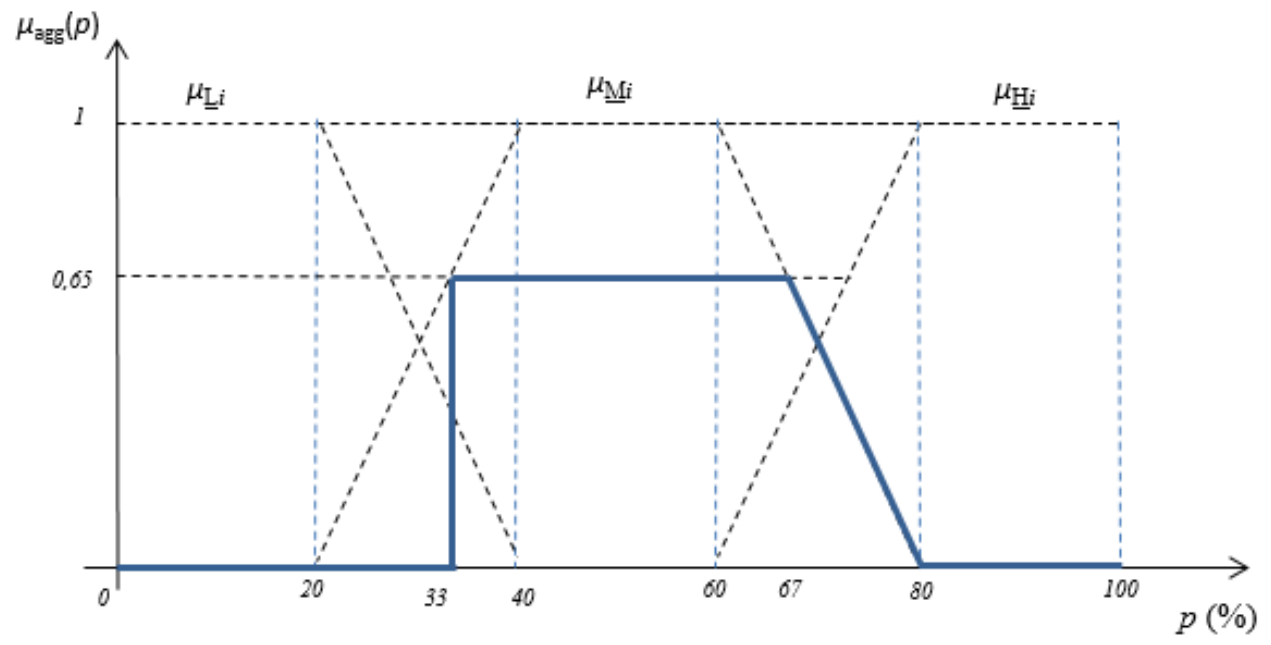

Fig. 3. The course of the output aggregate function $\mu_{\underline{A G G}}$ for $\mathrm{PS}_{\mathrm{CZ}} \%$ Source: Own processing. 


\section{Discussion and Conclusive Remarks}

The aim of the paper was to present a general fuzzy algorithm formulated within the Zadeh's fuzzy approach for solving a predictive economic problem under conditions of internal uncertainty of the model and external uncertainty relating to the entry data used. Such procedure offers an expected (predicted) objective result as an alternative to statistically expected values.

The fuzzy algorithm is presented and justified in view of the transformation of one of the important concepts of fuzzy logic, which is the extension principle, at the level of linguistic variables and their terms, within which the problem is solved. Furtheron, this algorithm is used to predict the change in the production of passanger cars in CZ for 2020 (the comparison with the official econometric forecast).

Under „normal“, i.e., an expected behaviour of economy, the entry data are partial components of the historical development of the indicators influencing, although vagualy, the trend of a target variable (the influencing indicators here are a change in Germany's gross domestic product, a change in the worldwide cars production and a change in the cars production in Germany, the target variable is a change in the production of passenger cars in CZ). Due to the COVID-19 outbreak the procedure of the fuzzy prediction following the expected trends is excluded. Instead, the expert scenarios of the possible variables' (indicators') development are taken into account.

The data of the indicators are used in the fuzzy model formulation phase, within which an expert (through the qualified interventions in the structure of the model and the formulation of inference rules) gets the opportunity to take into account his/her knowledge and experience, as well as in the process of solving a problem that is purely mechanical and independent of the human factor and in which these indicators play the role of external inputs to the fuzzy algorithm.

It consists of five basic steps, which are fuzzification, application of inference rules, further processing of intermediate results, aggregation and defuzzification. The contribution to the fuzzification process is the formulation of a fuzzification table, which makes the solution much more transparent and easier. Regarding the inference rules in the function of tools for partial transformations of inputs to an output, only two of their total number of 27 were used: $((\underline{\underline{L}}, \underline{M}, \underline{M}), \underline{M}),((\underline{M}, \underline{M}, \underline{M}), \underline{M})$. The right-hand sides of the two rules correspond with the predominant element strategy in formulating the system of inferential rules.

The result of the solution (the course of $\mu_{\underline{A G G}}$ function) at the level of terms of the linguistic variable $\triangle \mathrm{PS}_{\mathrm{CZ}} \%$ is shown in Fig. 3, in which the designation $\Delta \mathrm{PS}_{\mathrm{CZ}} \%$ is a notation abbreviation for the predicted change in the production of passenger cars in $\mathrm{CZ}$ expressed as a percentage of the highest drop $\triangle \mathrm{PS}_{\mathrm{CZ}} \%$ estimate derived from the official pessimistic GDP scenario iii. decrease wordwide. By recalculation of the distances of the centers of gravity of strongly delimited areas of the vertical coordinate axes to a value of the original scale, the prediction of $\triangle \mathrm{PS}_{\mathrm{CZ}} \%$ value for 2020 was obtained as $-34 \%$, which is slightly worse result than the 2020 econometric estimate that gives $-30 \%$ prediction.

\section{References}

1. Eurostat Newsrelease - euro indicators.[on-line] https://ec.europa.eu/eurostat/documents/2995521/10294804/4-13052020-APEN.pdf/dfa765ad-4a32-8135-f98f-69e565347750 (2020) 
2. Evgenidis, A., Papadamou, S., \& Siriopoulos, C. The yield spread's ability to forecast economic activity: What have we learned after 30 years of studies?. Journal of Business Research, 106, 221-232. (2020)

3. del Rio-Chanona, R. M., Mealy, P., Pichler, A., Lafond, F., \& Farmer, D. Supply and demand shocks in the COVID-19 pandemic: An industry and occupation perspective. arXiv preprint arXiv:2004.06759. (2020)

4. Gasiorek, M., Serwicka, I., \& Smith, A. Which manufacturing sectors are most vulnerable to Brexit. UK trade policy observatory. Briefing paper, 16. (2018)

5. Srivastava, M., \& Tyll, L. The effect of industry-specific networking behaviour on the internationalization performance of Czech SMEs. European Business Review. (2020)

6. Hašková, S. An alternative approach for estimating GDP growth rate: fuzzy prediction model. ACC Journal. (2019)

7. Zadeh, L. A. Fuzzy logic and approximate reasoning. Synthese, 30(3-4), 407-428. (1975)

8. Grabisch, M. The application of fuzzy integrals in multicriteria decision making. European journal of operational research, 89(3), 445-456. (1996)

9. Běhounek, L., \& Cintula, P. From fuzzy logic to fuzzy mathematics: A methodological manifesto. Fuzzy Sets and Systems, 157(5), 642-646. (2006)

10. Hašková, S., \& Fiala, P. A fuzzy approach for the estimation of foreign investment risk based on values of rating indices. Risk Management, 21(3), 183-199. (2019).

11. Statista Germany: Growth rate of the real gross domestic product (GDP) from 2009 to 2021. [on-line] https://www.statista.com/statistics/375203/gross-domestic-productgdp-growth-rate-in-germany/(2020)

12. Statista Estimated worldwide automobile production from 2000 to 2019. [on-line] https://www.statista.com/statistics/262747/worldwide-automobile-production-since2000/ (2020)

13. Statista Automobile production in Germany from 2007 to 2019. [on-line] https://www.statista.com/statistics/589254/car-production-germany/ (2020).

14. Europian Commission European Economic Forecast, Spring 2020. [on-line] https://ec.europa.eu/info/sites/info/files/economy-finance/ip125_en.pdf (2020). 